\title{
Transmaternal Exposure to Bisphenol A Modulates the Development of Oral Tolerance
}

\author{
YUSEI OHSHIMA, AKIKO YAMADA, SHUKO TOKURIKI, MOTOKO YASUTOMI, NEMUKO OMATA, \\ AND MITSUFUMI MAYUMI \\ Department of Pediatrics, Faculty of Medical Sciences, University of Fukui, Shimoaizuki, Matsuoka, Eiheiji-cho, Yoshida-gun, Fukui, \\ Japan, 910-1193
}

\begin{abstract}
Bisphenol A (BPA) is a representative endocrine disruptor that may have adverse effects on human health. Since the development of oral tolerance during infancy may play an important role in the prevention of food allergies, we examined whether transmaternal exposure to BPA influences the development of oral tolerance. To measure antigen-specific responses, female wild-type mice mated with male ovalbumin (OVA)-specific T-cell receptor transgenic (TCR-tg) mice were fed with BPA during pregnancy and while nursing. OVA was administered to OVA-TCR-tg offspring during their weaning period. Oral administration of both high and low doses of OVA suppressed OVA-specific cell proliferation and cytokine production in both BPA-exposed and nonexposed control mice, but the OVA-mediated suppression was significantly more diminished by the BPA exposure. The accumulation of $\mathrm{CD} 4{ }^{+} \mathrm{CD} 25^{+}$Foxp $3^{+} \mathrm{T}$ cells was diminished in the BPA-exposed offspring. Moreover, after low dose OVA administration, serum OVA-specific IgG1 and IgG2a levels were higher in the BPAexposed offspring than in nonexposed ones. Taken together, our results indicate that transmaternal exposure to BPA seems to modulate the mechanisms underlying tolerance induction; therefore, BPA may partially interrupt the development of oral tolerance. (Pediatr Res 62: 60-64, 2007)
\end{abstract}

$\mathrm{T}$ here has been a significant increase in the prevalence of allergic diseases, including food allergies, over the past few decades. It has been proposed that factors characteristic of modern lifestyles that may originate from the chemical, physical, biologic, or psychosocial environment play a role in the development of allergy $(1,2)$. In this context, exposure to environmental chemicals that were not previously present earlier in human history might be involved in the increase in allergic diseases. EDC are ubiquitous in the environment and have been documented to have deleterious effects in many species, including humans. Typical EDC are thought to disturb the effects of natural hormones, such as sex and thyroid hormones (3). Since these hormones normally influence the development and functioning of the immune system, as well as reproductive and central nervous systems (3), the possibil-

Received August 11, 2006; accepted February 22, 2007.

Correspondence: Yusei Ohshima, M.D., Ph.D., Department of Pediatrics, Faculty of Medical Sciences, University of Fukui, 23-3 Shimoaizuki, Matsuoka, Eiheiji-cho, Yoshida-gun, Fukui 910-1193, Japan; e-mail: yohshima@u-fukuki.ac.jp

This work was supported by a grant from the Long-range Research Initiative (LRI) by the Japan Chemical Industry Association (JCIA), a grant from the Pollution-related Health Damage Compensation and Prevention Association, and a grant from the 21st Century COE program. ity that environmental exposure to EDCs might also affect the immune system during development has been raised.

BPA [2,2-(4,4-dihydroxydiphenol) propane] is widely used in the manufacture of polycarbonate plastics, which serve as containers for foods and beverages and as a constituent of dental sealants $(4,5)$. Given its widespread use in consumer products, exposure of the human population to BPA is significant. BPA was recognized as a xenoestrogen due to its binding activity to estrogen receptors, and it plays either estrogenic or antiestrogenic roles in vitro $(6,7)$. Estrogen is known to have biphasic dose effects, with lower levels enhancing specific immune activities and higher levels, which occur during pregnancy, inhibiting them (8). Estrogen has been shown to expand the compartment of $\mathrm{CD} 4^{+} \mathrm{CD} 25^{+}$ regulatory $\mathrm{T}$ cells, which are crucial to the maintenance of tolerance (9). Therefore, BPA could potentially influence both immunity and tolerance. In fact, it was demonstrated that BPA increases the mitogen-induced proliferation of splenocytes and enhanced IL-4 production by Th2 cells in vitro and that BPA enhances Th2 and Th1 immune responses, depending on the doses of BPA administered in vivo (10-12). Although prenatal exposure to BPA has been shown to augment both Th1 and Th2 responses in adulthood (13), the effects of BPA on the development of oral tolerance have not yet been determined.

The key events leading to Th2-polarized immunity and allergy are initiated in utero and during the first year of life, and food allergy often appears in early clinical stages of the allergic march $(14,15)$. Since food allergies develop in genetically predisposed individuals, presumably when oral tolerance fails to develop normally or when it breaks down (16), we investigated the effects of transmaternal exposure to BPA through placenta and breast milk on the development of oral tolerance in neonates.

Accumulating evidence indicates that antigen-specific $\mathrm{T}$ cells play a crucial role in the pathogenesis of all forms of food allergies (17), and that T-cell anergy, clonal deletion, and active suppression by regulatory $\mathrm{T}$ cells play a central role in the development of oral tolerance (18). Because the precursor frequency of antigen-specific T cells present in normal mice is

Abbreviations: BPA, bisphenol A; EDC, endocrine-disrupting compounds; OVA, ovalbumin; OVA-TCR-Tg, ovalbumin-specific T-cell receptor transgenic; TCR, T-cell receptor 
too low to detect antigen-specific T-cell responses, we took advantage of our recent study showing that oral administration of OVA induced tolerance in transgenic mice with $\mathrm{T}$ cells bearing OVA-specific TCR (OVA-TCR-Tg), in which we can easily track OVA-specific T-cell responses without prior immunization against OVA, and we can also evaluate the development of oral tolerance by using splenocytes on behalf of mononuclear cells of mesenteric lymph nodes $(19,20)$. We found that transmaternal exposure to BPA partially diminished oral antigen-induced hypo-responsiveness and diminished the accumulation of $\mathrm{CD} 4{ }^{+} \mathrm{CD} 25^{+} \mathrm{T}$ cells. BPA exposure also modulated humoral immune responses.

\section{MATERIALS AND METHODS}

Animals and treatment with BPA. DO11.10 mice with T cells bearing the transgenic TCR that recognizes the 323-339 peptide fragment of OVA (OVA-TCR-Tg) were a generous gift from Dr. S. Sakaguchi (Kyoto University, Kyoto, Japan). Wild-type female Balb/c mice, 8 wk of age, were crossed with heterozygous OVA-TCR-Tg stud males and were fed with diets containing 0, 0.1, or 1 ppm BPA (Wako Pure Chemical Industries, Ltd., Osaka, Japan) during gestational and nursing periods. Male offspring, heterozygous for OVA-TCR-Tg, were randomly selected from separate litters and used in individual experiments. Each experiment included six to eight animals and each experiment was replicated four or six times, producing aggregate data from 24 to 48 mice. These mice were bred under standard pathogen-free conditions in the animal facility of the University of Fukui. All animal experiments were performed in accordance with institutional guidelines as approved by the Animal Care Review Board of the University of Fukui.

Oral antigen administration and preparation of mononuclear cells from the spleen. Randomly selected OVA-TCR-Tg male offspring of BPA-fed or nonfed dams were fed by intragastric intubation at the age of 14, 16, and $18 \mathrm{~d}$ either with $20 \mathrm{mg} /$ dose (high dose) or with $0.2 \mathrm{mg} / \mathrm{dose}$ (low dose) OVA (Sigma Chemical Co.-Aldrich Co., St. Louis, MO) dissolved in $0.1 \mathrm{~mL}$ PBS, or with PBS alone (control). At the age of $21 \mathrm{~d}$, spleens were removed aseptically and were gently crushed and filtered through a $40 \mu \mathrm{m}$ nylon mesh (Falcon, Bedford, MA). Spleen cells were incubated for $5 \mathrm{~min}$ in Tris-buffered $\mathrm{NH}_{4} \mathrm{Cl}$ to remove red blood cells. The mononuclear cell suspensions were prepared in cell culture medium consisting of RPMI 1640 supplemented with $50 \mathrm{mM}$ HEPES, $100 \mathrm{U} / \mathrm{mL}$ penicillin, $100 \mu \mathrm{g} / \mathrm{mL}$ streptomycin, $2 \times 10^{-5} \mathrm{M}$ 2-mercaptoethanol, and 10\% heat inactivated FCS (Sigma Chemical Co.Aldrich Co.)

Antigen-specific cell proliferation and cytokine production. The mononuclear cells $\left(1 \times 10^{5} /\right.$ well $)$ were cultured for $92 \mathrm{~h}$ in a 96-well round bottom plate (Falcon) with various concentrations of OVA. Cell proliferation was assessed by adding $1 \mu \mathrm{Ci} /$ well of $\left[\right.$ methyl $\left.-{ }^{3} \mathrm{H}\right]$ thymidine $(10 \mathrm{Ci} / \mathrm{mmol}$; Amersham Bioscience Co. Piscataway NJ) during the last $16 \mathrm{~h}$ of culture. Incorporation of [methyl- ${ }^{3} \mathrm{H}$ ] thymidine was measured by liquid scintillation counting. All determinations were performed in triplicate and reported as the mean counts per minute (cpm). Before the thymidine pulse, supernatants were collected and cytokine contents were determined utilizing an ELISA.

Cytokine measurements. IL-4, IL-13, and interferon (IFN)- $\gamma$ in the above mentioned culture supernatants were measured by a two-site sandwich ELISA, using the protocol recommended by the antibody suppliers. Antibody pairs and standard recombinant cytokines for the ELISA were purchased from BD Biosciences (San Jose, CA) and PeproTech Inc. (Rocky Hill, NJ), respectively. IL-13 ELISA kit was from R \& D Systems, Inc. (Minneapolis, MN).

Measurement of ova-specific antibodies. Dam and puppy blood was collected when the offspring reached $21 \mathrm{~d}$ of age. Serum levels of OVAspecific IgG1, IgG2a, and IgE were determined by ELISA. In brief, microtiter plates (Nalgenunc International Co. Tokyo, Japan) were coated with 100 $\mu \mathrm{L} /$ well of OVA $(100 \mu \mathrm{g} / \mathrm{mL})$ overnight at $4^{\circ} \mathrm{C}$ and then were blocked by incubation with ELISA blocking reagent (Roche Diagnostics Co. Tokyo, Japan) for $4 \mathrm{~h}$ at room temperature. After washing four times with PBS/0.05\% Tween 20, the plates were incubated with $100 \mu \mathrm{L} /$ well of serially diluted pooled standard serum or diluted serum samples overnight at $4^{\circ} \mathrm{C}$. After washing four times with PBS/0.05\% Tween 20, plates were then incubated with $100 \mu \mathrm{L} /$ well of biotin-conjugated rat anti-mouse IgG1, IgG2a, or IgE $\mathrm{MAb}$ (BD Biosciences) at $2 \mu \mathrm{g} / \mathrm{mL}$ in PBS/1\% BSA for $2 \mathrm{~h}$, followed by washing four times with PBS/ $0.05 \%$ Tween 20 and then a $2 \mathrm{~h}$ incubation with $100 \mu \mathrm{L} /$ well of horseradish peroxidase-conjugated streptavidin $(\times 4000$ in PBS/1\% BSA, Pierce Biotechnology, Inc. Rockford, IL). The plates were developed with the TMB microwell peroxidase substrate system (Kirkegaard and Perry Laboratories Inc., Guildford, UK). Standard curves for IgG1 and $\mathrm{IgG} 2 \mathrm{a}$ were run using hyperimmune anti-OVA sera, which was diluted from $1: 320,000$ and $1: 10,000$ down to extinction and was assigned an arbitrary value of 10,000 units. The number of arbitrary units of antibody that sample sera contained, relative to the standard, was calculated. Hyperimmune sera were obtained from mice immunized intraperitoneally with $10 \mu \mathrm{g}$ OVA adsorbed on $100 \mu \mathrm{g} \mathrm{Al}(\mathrm{OH})_{3}$ at $\mathrm{d} 7$ and 14. Blood from untreated mice was used to assess background levels of unspecific binding.

$\boldsymbol{m} \boldsymbol{A} \boldsymbol{b}$ and flow-cytometry. FITC-conjugated anti-mouse CD3, CD8, and $\mathrm{CD} 25 \mathrm{mAbs}$, and phycoerythrin (PE)-conjugated anti-CD4 MAb were purchased from BD Biosciences. FITC-conjugated KJ1-26, recognizing the TCR specific to OVA and PE-Cy5-conjugated anti-Foxp3 MAb with corresponding isotype control rat IgG2a were purchased from Caltag (Burlingame, CA) and eBioscience Inc. (San Diego, CA), respectively. Cells were stained using standard procedures. For intracellular staining of Foxp3, the cells were pretreated with BD Cytofix/Cytoperm. The cells were then analyzed on a FACS Calibur (BD Biosciences).

Measurement of serum BPA. Serum levels of BPA were determined using an ELISA kit (Wako Pure Chemical Industries, Ltd.). The minimal detection limit of the assay was $0.2 \mathrm{ng} / \mathrm{mL}$.

Data compilation and statistical analysis. The pooled data obtained from at least four independent experiments are presented as the mean \pm SD of each group $(n=6$ or 8$)$. The concentrations of OVA-specific IgG were logarithmically transformed and normalized. Differences between the two groups were analyzed by nonpaired $t$ test, unless an $F$-test revealed that the variances of the two groups were statistically different. When the variances were significantly different, Welch's test was used instead of the nonpaired $t$ test. A $p$ value of less than 0.05 denoted a statistically significant difference.

\section{RESULTS}

\section{Phenotypes of splenocytes from transmaternally exposed} offspring. Administration of 0.1 or $1 \mathrm{ppm}$ BPA to pregnant mice did not affect the gender ratio or the ratio of wild-type heterozygous OVA-TCR-tg offspring (data not shown), indicating that these concentrations of BPA did not affect the ontogenesis of OVA-TCR-tg mice. However, the offspring born to the dams fed with $1 \mathrm{ppm}$ BPA exhibited lower percentages of OVA-TCR expressing KJ1-26 ${ }^{+} \mathrm{T}$ cells in splenocytes, compared with those born to nonfed dams (Fig. 1).

To examine the antigen-specific responsiveness of naïve $\mathrm{T}$ cells that were not sensitized to OVA in vivo, the splenocytes
A

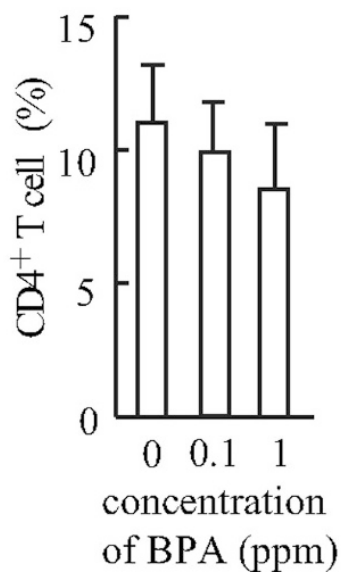

B

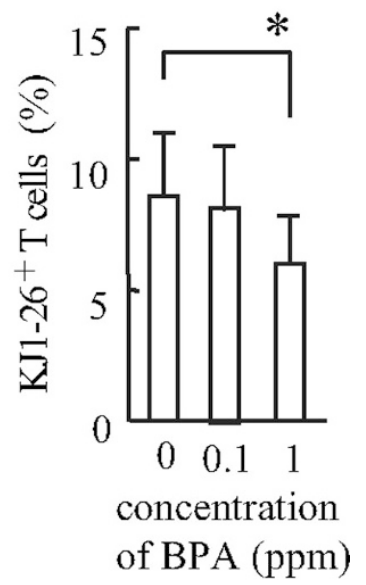

Figure 1. Effects of transmaternal exposure to BPA on the percentages of OVA-specific TCR-bearing T cells in the spleen. Dams were fed with the indicated concentration of BPA. The percentages of $\mathrm{CD}^{+}$cells $(A)$ and $\mathrm{KJ} 1-26^{+}$cells $(B)$ in the splenocytes of the offspring at the age of $21 \mathrm{~d}$ were determined. Shown are the mean $\pm \operatorname{SD}(n=8)$ of the pooled data obtained from four independent experiments. ${ }^{*} p<0.05$ ( $t$ test). 
$\mathrm{A}$

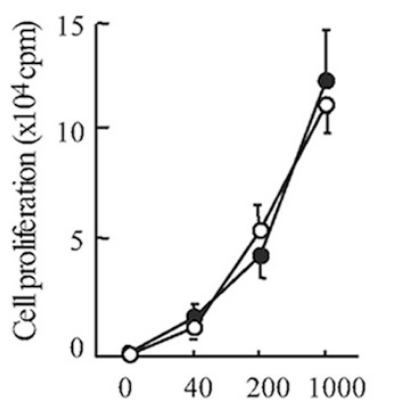

concentration of OVA $(\mu \mathrm{g} / \mathrm{ml})$

$\mathrm{C}$

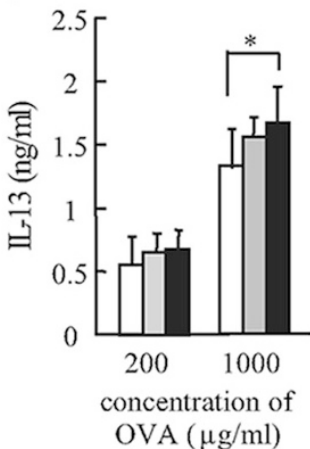

B

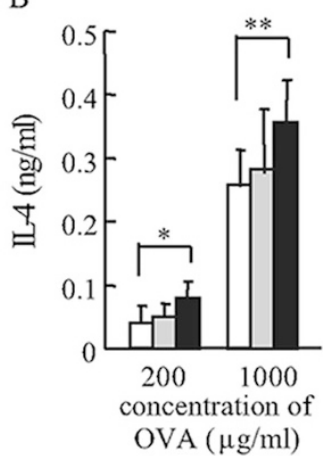

D

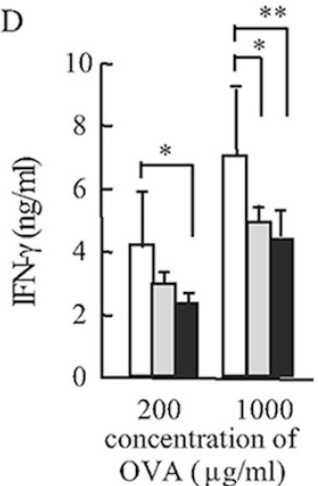

Figure 2. Transmaternal exposure to BPA modulated antigen-specific cytokine production profiles. Dams were fed with $0.1 \mathrm{ppm}$ (gray bars), $1 \mathrm{ppm}$ (closed circles and bars) of BPA, or with no BPA (open circles and bars) during gestation and lactating periods. Splenocytes purified from OVATCR-tg offspring were stimulated with the indicated concentrations of OVA in vitro. Cell proliferation $(A)$ and IL-4 $(B)$, IL-13 $(C)$, and IFN- $\gamma(D)$ in the supernatants were measured by thymidine incorporation and ELISA, respectively. Shown are the mean $\pm \operatorname{SD}(n=8)$ of the pooled data obtained from four independent experiments. ${ }^{*} p<0.05$, $* * p<0.01$ ( $t$ test and Welch's test).

of the offspring that had not been administered OVA were stimulated with OVA in vitro. As shown in Figure 2A, transmaternal exposure to $1 \mathrm{ppm}$ BPA did not affect OVA-specific cell proliferation. Of note, the splenocytes of the offspring preexposed to $1 \mathrm{ppm}$ BPA produced more IL-4 and IL-13, and less IFN- $\gamma$, in response to OVA than did nonexposed ones (Fig. 2, $B-D$ ), suggesting that transmaternal exposure to BPA led $\mathrm{T}$ cells to acquire a Th2-favoring predisposition in the offspring.

Effects of BPA on the development of hyporesponsiveness of antigen-specific T cells. We next examined how transmaternal exposure to BPA influenced the $\mathrm{T}$ cells that were primed in vivo with orally administered antigen to acquire antigen-specific responsiveness. To this end, we measured OVA-specific proliferation and cytokine-producing profiles of splenocytes from the mice that received oral administration of OVA three times. Using $0.1 \mathrm{ppm}$ BPA resulted in a similar tendency of the splenocyte phenotypes to that elicited by 1 ppm BPA, but some of these tendencies were not statistically significant. Therefore, we used $1 \mathrm{ppm}$ BPA in subsequent experiments. As shown in Figure 3, the OVA-specific cell proliferation of the offspring splenocytes was suppressed by oral administration of OVA, whereas splenocytes from mice preexposed to BPA retained a significantly higher proliferation rate than that of nonexposed mice. Oral OVA adminis-
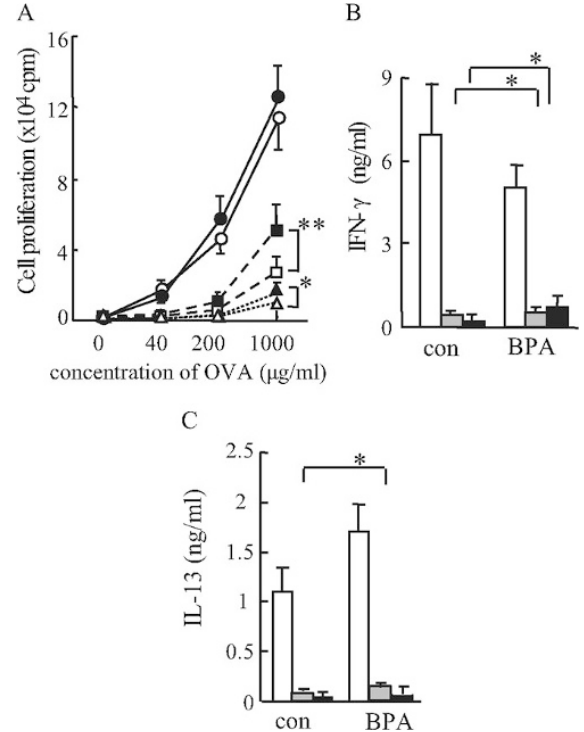

Figure 3. Transmaternal exposure to BPA inhibited oral tolerance induction. In A, low (squares) or high (triangles) doses of OVA, or PBS (circles) were administered intragastrically to BPA-exposed offspring (closed symbols) and to nonexposed offspring (open symbols). Splenocytes were stimulated with the indicated concentrations of OVA. In B and C, low (gray bars) or high (closed bars) doses of OVA, or PBS (open bars), were given to the offspring. Splenocytes were stimulated with $1000 \mu \mathrm{g} / \mathrm{mL}$ OVA. IFN- $\gamma(B)$ and IL-13 $(C)$ in the supernatant was measured by ELISA. Shown are the mean $\pm \mathrm{SD}$ $(n=8)$ of the pooled data obtained from six independent experiments. $* p<$ $0.05, * * p<0.01$ ( $t$ test and Welch's test).

tration also suppressed OVA-specific IFN- $\gamma$ production (Fig. $3 B)$. After oral administration of OVA, the splenocytes of offspring preexposed transmaternally to BPA produced significantly more IFN- $\gamma$ and IL-13 than did those of nonexposed offspring. After oral administration of OVA, no measurable levels of IL-2 or IL-4 production were detected (data not shown).

Effects of BPA on clonal deletion and $\mathrm{CD}^{+} \mathrm{CD} 25^{+} \mathrm{T}$ cell-induction. As previously reported (20-22), without transmaternal exposure to BPA, oral administration of high-dose $(20 \mathrm{mg})$ OVA decreased the number and percentage of OVAspecific TCR-expressing $\mathrm{T}$ cells and increased the number and percentage of $\mathrm{CD} 4^{+} \mathrm{CD} 25^{+} \mathrm{T}$ cells (Fig. 4). These $\mathrm{CD} 4^{+} \mathrm{CD} 25^{+} \mathrm{T}$ cells expressed Foxp3, which is a critical transcription factor for the differentiation of regulatory $\mathrm{T}$ cells (Fig. 5), and exhibited a regulatory function (data not shown), confirming the original report $(21,22)$, in that they seem to correspond to regulatory T cells. Administration of low-dose $(0.2 \mathrm{mg})$ OVA also increased the number of $\mathrm{CD} 4{ }^{+} \mathrm{CD} 25^{+} \mathrm{T}$ cells, but these changes were not statistically significant. In mice preexposed to BPA, oral administration of high-dose OVA decreased the OVA-specific $\mathrm{T}$ cells but failed to induce the accumulation of $\mathrm{CD} 4{ }^{+} \mathrm{CD} 25^{+} \mathrm{T}$ cells and Foxp $3^{+} \mathrm{CD} 4{ }^{+}$cells (Figs. 4 and 5).

Effects of BPA on antigen-specific immunoglobulin production. After three administrations of low-dose oral OVA, OVA-specific IgG1 and IgG2a, which are generally produced in Th2 and Th1 responses, respectively, were detected in the serum (Fig. 6). The serum levels of OVA-specific IgG1 and IgG2a were higher in BPA-exposed offspring than in nonex- 
A

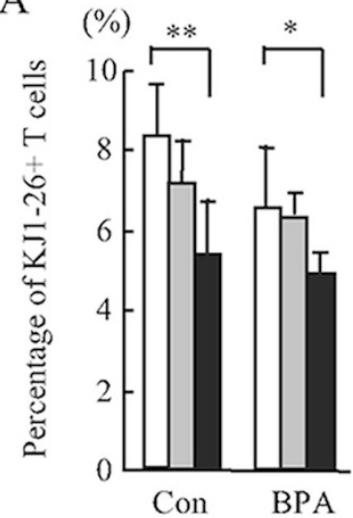

$\mathrm{C}$

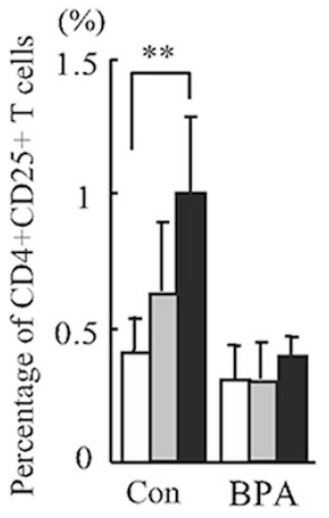

B

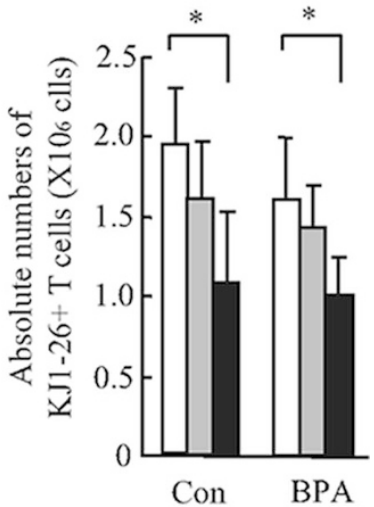

D

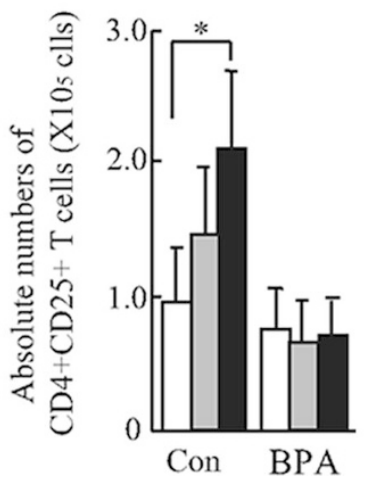

Figure 4. Effects of BPA on clonal deletion and the accumulation of $\mathrm{CD} 25^{+} \mathrm{CD} 4^{+} \mathrm{T}$ cells. Low (gray bars) or high (closed bars) doses of OVA, or PBS (open bars), were given intragastrically to BPA-exposed offspring and to nonexposed offspring. The percentages $(A$ and $C$ ) and absolute numbers $(B$ and $D$ ) of OVA-TCR-bearing T cells $(A$ and $B)$ and $\mathrm{CD} 4{ }^{+} \mathrm{CD} 25^{+} \mathrm{T}$ cells $(B$ and $D)$ were determined. Shown are the mean $\pm \mathrm{SD}(n=8)$ of the pooled data obtained from six independent experiments. $* p<0.05$, ${ }^{* *} p<0.01$ ( $t$ test and Welch's test).

posed ones. Differences in the levels of OVA-specific IgG1 and $\operatorname{IgG} 2 \mathrm{a}$ were not detected in the mice given high doses of OVA. Because of the sensitivity of the ELISA, OVA-specific IgE was not detected in the serum after OVA administration (data not shown).

A

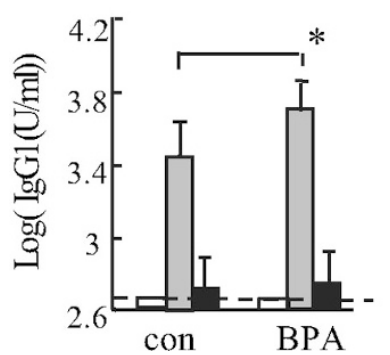

B

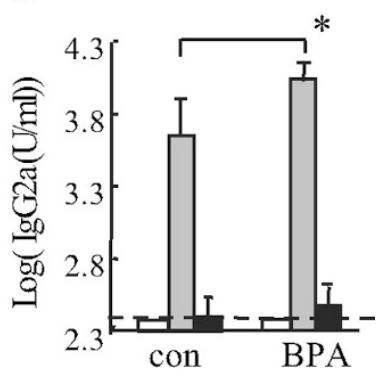

Figure 6. Transmaternal exposure to BPA altered humoral immune responses. Low (gray bars) or high (closed bars) doses of OVA, or PBS (open bars), were given intragastrically to BPA-exposed and to nonexposed male offspring. OVA-specific $\operatorname{IgG1}(A)$ and $\operatorname{IgG} 2(B)$ in the serum of BPA-exposed offspring and nonexposed offspring at the age of $21 \mathrm{~d}$ were measured by ELISA. The broken lines indicate the background of the ELISA. Shown are the mean $\pm \mathrm{SD}(n=8)$ of the pooled data obtained from six independent experiments. ${ }^{*} p<0.01$ ( $t$ test and Welch's test).

Serum levels of BPA. Finally, to assess the exposure levels of BPA, we measured serum BPA of dams fed with $1 \mathrm{ppm}$ BPA and serum from their offspring at the age of $21 \mathrm{~d}$. The serum BPA levels of mother mice and offspring were $1.41 \pm$ $0.66 \mathrm{ng} / \mathrm{mL}(0.70-2.33 \mathrm{ng} / \mathrm{mL})$ and $3.971 \pm 2.40 \mathrm{ng} / \mathrm{mL}$ $(0-6.74 \mathrm{ng} / \mathrm{mL})$, respectively.

\section{DISCUSSION}

We have demonstrated that transmaternal exposure to BPA modifies the intrinsic cytokine producing properties of antigen inexperienced naïve $\mathrm{T}$ cells in vivo in an OVA-specific TCR-tg mouse model. It has been shown that the intrinsic cytokine-producing property of cord blood $\mathrm{T}$ cells is associated with the subsequent development of atopic diseases (23). Thus, intrauterine exposure to BPA might influence the acquisition of an allergic predisposition. Moreover, transmaternal exposure to BPA diminishes oral antigen-induced suppression in antigen-specific proliferative and cytokine-producing responses, and this exposure modulates antigen-specific $\operatorname{IgG}$ production in the offspring. Depending on the amount and methods of food antigen intake, transmaternal exposure to BPA may interfere with the development of oral tolerance and thereby lead to the emergence of food allergies.

B
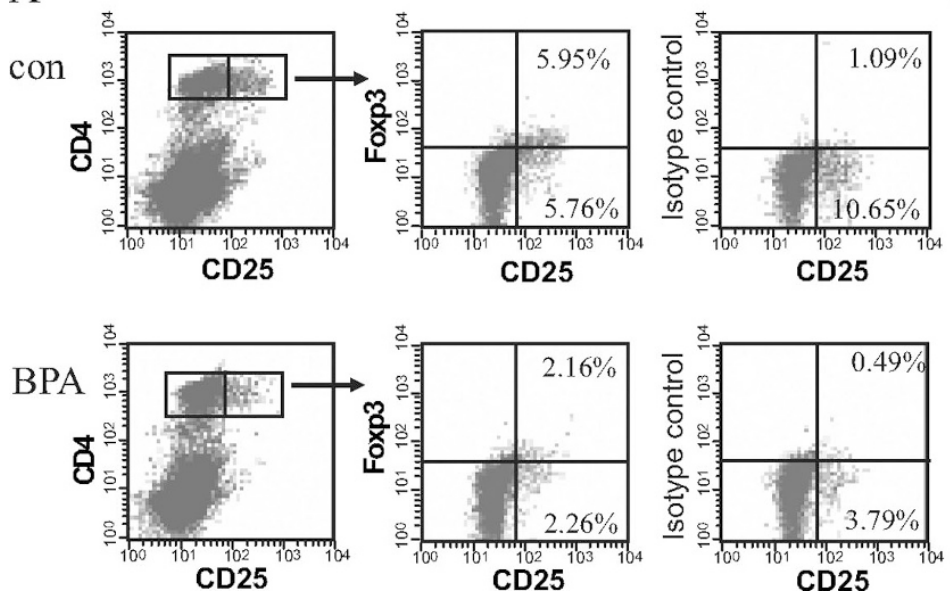

Figure 5. Effects of BPA on the accumulation of $\mathrm{Foxp}^{+} \mathrm{CD}^{+}{ }^{+} \mathrm{T}$ cells. High doses of OVA (closed bars), or PBS (open bars), were given intragastrically to BPAexposed offspring and to nonexposed offspring. The Foxp $3^{+}$expression in the $\mathrm{CD} 4^{+}$splenocytes was measured by flow cytometry. Values represent the presumptive percentages of Foxp $3^{+} \mathrm{CD} 25^{+} \mathrm{CD} 4^{+}$ cells and Foxp $3^{-} \mathrm{CD} 25^{+} \mathrm{CD} 4^{+}$cells, because the $\mathrm{CD} 25^{+} \mathrm{CD} 4^{+}$subsets seem to be a homogenous population in terms of Foxp3 expression (A). In $B$, data indicate the presumptive percentage of Foxp $3^{+}$ cells in CD4 $+\mathrm{T}$ cells. Shown are the mean $\pm \operatorname{SD}(n=6)$ of the pooled data obtained from four independent experiments. ${ }^{*} p<0.05$ ( $t$ test $)$. 
Consistent with previous reports (20-22), oral administration of OVA seems to induce both clonal deletion and accumulation of $\mathrm{CD} 4{ }^{+} \mathrm{CD} 25^{+}$regulatory $\mathrm{T}$ cells. Transmaternal exposure to BPA did not prevent clonal deletion of OVAspecific T cells by oral administration of OVA (Fig. 4, A and $B)$. Therefore, a failure to induce $\mathrm{CD} 4{ }^{+} \mathrm{CD} 25^{+} \mathrm{T}$ cells may account for the higher proliferative responses observed in the splenocytes from OVA-fed mice that were preexposed to BPA, as compared with OVA-fed nonexposed mice (Figs. 4, $C$ and $D$ and $3 A$ ).

It has been shown that estradiol expands $\mathrm{CD} 4{ }^{+} \mathrm{CD} 25^{+}$ regulatory T cells in vivo via estrogen receptor $\alpha$ and that BPA shows either agonist or antagonist activity via estrogen receptor $\alpha$, depending on the cell type $(7,9)$. Thus, the inhibitory effects of BPA on the $\mathrm{CD} 4{ }^{+} \mathrm{CD} 25^{+} \mathrm{T}$-cell compartment might be explained by its antiestrogenic activity. Because it has been speculated that BPA may also act as an oxidative stress inducer, an inhibitor of apoptosis, and a thyroid hormone antagonist, further studies are necessary to clarify the mechanisms underlying the inhibition of $\mathrm{CD} 4{ }^{+} \mathrm{CD} 25^{+} \mathrm{T}$-cell induction (24-26).

It has been shown that transient priming of cytokine production before the development of oral tolerance occurs after low dose of oral antigen administration (27). Thus, oral administration of low-dose OVA may cause cytokine production in vivo and thereby induce OVA-specific $\operatorname{IgG}$ production. After OVA administration, the higher residual cytokine producing ability of the splenocytes might explain the higher serum levels of OVA-specific IgG observed in low-dose OVA-fed offspring that were preexposed to BPA, as compared with nonexposed offspring.

The serum BPA concentrations of the dams and their offspring were one order of magnitude higher than the previously reported levels in human umbilical cords and placental tissue $(28,29)$. Although there is no definitive evidence indicating that oral ingestion of BPA existing in the environment has adverse effects on humans, further studies are warranted to assess the effects of BPA on the development of the immune system and on allergic diseases. Moreover, this oral tolerance model using OVA-TCR-tg mice might be useful for assessing the toxicity of chemical compounds.

\section{REFERENCES}

1. Ring J, Kramer U, Schafer T, Behrendt H 2001 Why are allergies increasing? Curr Opin Immunol 13:701-708

2. McGeady SJ 2004 Immunocompetence and allergy. Pediatrics 113:1107-1113

3. Damstra T, Barlow S, Bergman A, Kavlock R, Van Der Kraak G. 2002 Global assessment of the state-of-the-science of endocrine disruptors. World Health Organization, Geneva, pp 51-88

4. Feldman D 1997 Estrogens from plastic - are we being exposed? Endocrinology 138:1777-1779
5. Noda M, Komatsu H, Sano H 1999 HPLC analysis of dental resin composites components. J Biomed Mater Res 47:374-378

6. Hiroi H, Tsutsumi O, Takeuchi T, Momoeda M, Ikezuki Y, Okamura A, Yokota H, Taketani Y 2004 Differences in serum bisphenol a concentrations in premenopausal normal women and women with endometrial hyperplasia. Endocr J 51:595-600

7. Kurosawa T, Hiroi H, Tsutsumi O, Ishikawa T, Osuga Y, Fujiwara T, Inoue S, Muramatsu M, Momoeda M, Taketani Y 2002 The activity of bisphenol A depends on both the estrogen receptor subtype and the cell type. Endocr J 49:465-471

8. Salem ML, Matsuzaki G, Kishihara K, Madkour GA, Nomoto K 2000 Beta-estradiol suppresses $\mathrm{T}$ cell-mediated delayed-type hypersensitivity through suppression of antigen-presenting cell function and Th1 induction. Int Arch Allergy Immunol 121:161-169

9. Polanczyk MJ, Carson BD, Subramanian S, Afentoulis M, Vandenbark AA, Ziegler $\mathrm{SF}$, Offner H 2004 Estrogen drives expansion of the $\mathrm{CD} 4^{+} \mathrm{CD} 25^{+}$regulatory T cell compartment. J Immunol 173:2227-2230

10. Jontell M, Hanks CT, Bratel J, Bergenholtz G 1995 Effects of unpolymerized resin components on the function of accessory cells derived from the rat incisor pulp. J Dent Res 74:1162-1167

11. Tian X, Takamoto M, Sugane K 2003 Bisphenol A promotes IL-4 production by Th2 cells. Int Arch Allergy Immunol 132:240-247

12. Yoshino S, Yamaki K, Yanagisawa R, Takano H, Hayashi H, Mori Y 2003 Effects of bisphenol A on antigen-specific antibody production, proliferative responses of lymphoid cells, and TH1 and TH2 immune responses in mice. Br J Pharmacol 138:1271-1276

13. Yoshino S, Yamaki K, Li X, Sai T, Yanagisawa R, Takano H, Taneda S, Hayashi H, Mori Y 2004 Prenatal exposure to bisphenol A up-regulates immune responses, including T helper 1 and T helper 2 responses, in mice. Immunology 112:489-495

14. Prescott SL, Macaubas C, Holt BJ, Smallacombe TB, Loh R, Sly PD, Holt PG 1998 Transplacental priming of the human immune system to environmental allergens: universal skewing of initial $\mathrm{T}$ cell responses toward the Th2 cytokine profile. J Immunol 160:4730-4737

15. Prescott SL, Macaubas C, Smallacombe T, Holt BJ, Sly PD, Holt PG 1999 Development of allergen-specific T-cell memory in atopic and normal children. Lancet 353:196-200

16. Sampson HA 2004 Update on food allergy. J Allergy Clin Immunol 113:805-819

17. Eigenmann PA 2002 T lymphocytes in food allergy: overview of an intricate network of circulating and organ-resident cells. Pediatr Allergy Immunol 13:162171

18. Chehade M, Mayer L 2005 Oral tolerance and its relation to food hypersensitivities. J Allergy Clin Immunol 115:3-12

19. Weiner HL 2001 Oral tolerance: immune mechanisms and the generation of Th3-type TGF-beta-secreting regulatory cells. Microbes Infect 3:947-954

20. Omata N, Ohshima Y, Yasutomi M, Yamada A, Karasuyama H, Mayumi M 2005 Ovalbumin-specific IgE modulates ovalbumin-specific T-cell response after repetitive oral antigen administration. J Allergy Clin Immunol 115:822-827

21. Zhang X, Izikson L, Liu L, Weiner HL 2001 Activation of $\mathrm{CD} 25^{+} \mathrm{CD} 4^{+}$regulatory $\mathrm{T}$ cells by oral antigen administration. J Immunol 167:4245-4253

22. Thorstenson KM, Khoruts A 2001 Generation of anergic and potentially immunoregulatory CD25 $+\mathrm{CD} 4 \mathrm{~T}$ cells in vivo after induction of peripheral tolerance with intravenous or oral antigen. J Immunol 167:188-195

23. Ohshima Y, Yasutomi M, Omata N, Yamada A, Fujisawa K, Kasuga K, Hiraoka M, Mayumi M 2002 Dysregulation of IL-13 production by cord blood CD4 ${ }^{+}$T cells is associated with the subsequent development of atopic disease in infants. Pediatr Res 51:195-200

24. Bindhumol V, Chitra KC, Mathur PP 2003 Bisphenol A induces reactive oxygen species generation in the liver of male rats. Toxicology 188:117-124

25. Diel P, Olff S, Schmidt S, Michna H 2002 Effects of the environmental estrogens bisphenol A, o, p'-DDT, p-tert-octylphenol and coumestrol on apoptosis induction, cell proliferation and the expression of estrogen sensitive molecular parameters in the human breast cancer cell line MCF-7. J Steroid Biochem Mol Biol 80:61-70

26. Zoeller RT, Bansal R, Parris C 2005 Bisphenol-A, an environmental contaminant that acts as a thyroid hormone receptor antagonist in vitro, increases serum thyroxine, and alters RC3/neurogranin expression in the developing rat brain. Endocrinology 146:607-612

27. Marth T, Ring S, Schulte D, Klensch N, Strober W, Kelsall BL, Stallmach A, Zeitz M 2000 Antigen-induced mucosal $\mathrm{T}$ cell activation is followed by Th1 T cell suppression in continuously fed ovalbumin TCR-transgenic mice. Eur J Immunol 30:3478-3486

28. Schonfelder G, Wittfoht W, Hopp H, Talsness CE, Paul M, Chahoud I 2002 Parent bisphenol A accumulation in the human maternal-fetal-placental unit. Environ Health Perspect 110:A703-A707

29. Takeuchi T, Tsutsumi O 2002 Serum bisphenol a concentrations showed gender differences, possibly linked to androgen levels. Biochem Biophys Res Commun 291:76-78 